\title{
Types of Vignettes and Ethical Decision-Making among Business Education Students
}

\author{
Prisca Mary Oluoch ${ }^{1}$, Paul Amollo Odundo ${ }^{2}$, John Mwangi ${ }^{2} \&$ Charles Richard Oyier ${ }^{3}$ \\ ${ }^{1}$ Kenya School of Government, Kenya \\ ${ }^{2}$ Department of Educational Communication and Technology, University of Nairobi, Kenya \\ ${ }^{3}$ Cascading Solutions, Kenya \\ Correspondence: Paul Amollo Odundo, Department of Educational Communication and Technology, University \\ of Nairobi, Kenya. E-mail: odundopaul@yahoo.com
}

Received: June 18, 2018

Accepted: August 6, 2018

Online Published: September 28, 2018

doi:10.5539/ijbm.v13n10p249

URL: https://doi.org/10.5539/ijbm.v13n10p249

\begin{abstract}
Learner-centered experiential approaches such as adoption of vignettes focus on practical experiences and applications in teaching business ethics. Vignettes of different types provide scenarios of events that are logical in order to help learners develop an ethical sensitivity that would influence their decision-making skill. This study focused on adoption of narrative, illustrations, repertoires, documentaries or scripts used as instructional resources for instilling ethical sensitivity among business education students. The study adopted contingency framework for ethical decision-making and targeted 102 year-three business education students at University of Nairobi. Through random sampling 58 students provided information, which was descriptively analysed. Study findings indicated that $93.6 \%$ business education students agreed that narratives, $81.8 \%$ illustration, $78.6 \%$ repertoire, $90.9 \%$ documentaries and $97.0 \%$ scripts enhance decision-making. The study recommended that teachers be advised to adopted different types of vignettes in teaching, schools provide budgetary allocation for vignettes production and further research on to establish how much vignettes have been used in schools for business studies.
\end{abstract}

Keywords: vignettes types, ethical decision-making, ethical sensitivity

\section{Introduction}

Enhancing ethical skills-set would make business education learners have appropriate behaviour later as teachers. As noted by Oluoch and Odundo (2018) instilling ethical decision-making requires experiential learning approaches such as adoption of vignettes. Adoption of vignettes in teaching introduces a wide variety of business scenarios in class and enhances ethical sensitivity among learners. Supporting this position, Mazanec (2005) argued that different types of vignettes can be adopted to prompt critical and ethical thinking among business education students necessary in decision-making. Vignettes can be narrative, illustrations, repertoires, documentaries or scripts used as instructional resources for instilling ethical sensitivity among business education students. In their work on budget planning for instructional resources Oyier, Odundo, Ngaruiya and Mwangi (2017) acknowledged that variety of teaching and learning materials enhances learners' experience. To assist in understanding concepts in business ethics, this study considered adoption of variety of vignettes as experiential learning instructional resources, as a means of entrenching ethical sensitivity.

According to Odundo and Gunga (2013), learner-centered experiential approaches such as adoption of vignettes focus on practical experiences and applications. Vignettes of different types should provide scenarios of events that are logical in order to help learners develop an ethical sensitivity that would influence their decision-making skill. As noted by Harland (2014) adoption of the right type of vignettes would easily lead to advancements and the development of ideological thinking and ethical decision-making. Acknowledging that vignettes vary in types Bentley (2012) asserted that their adoption helps in gaining better understanding of different ethical issues in the business world. Further, Spencer et al. (2015) posits that as an experiential learning approach vignettes adoption provide educational experiences that enhance critical thinking and ethical sensitivity among learners. Teaching business ethics using experiential learning strategies may involve a wide variety of vignettes to generate interest, promote critical thinking. This study is an attempt to establish the effect of vignettes in form of 
stories, illustrations, repertoires, documentaries and scripts on ethical decision-making among business studies learners at the University of Nairobi.

\subsection{Narrative and Ethical Decision-Making}

Written narratives are one of the more common applications of the vignette technique. Sims and Sauser (2011) asserted that when narratives are used teachers find easy to establish the unique ideas, insights and challenges faced by individual learners in making ethical decisions. The narratives may be teacher or learner generated. In teaching education students business ethics, narratives would provide learners with practical ethical dilemmas from which learners develop ethical sensitivity as a learning outcome. In support of this argument McCarron and Stewart (2011) argued that adoption of vignettes narratives would help learners in problem analysis and in developing judgment criteria from varied perspectives. In this regard narratives would help learners to objectively come up with ethical decisions in business and hopefully be more confident in implementation. Further, Melé (2012) writing on management ethics noted that narratives help learners to develop personal convictions on ethical issues from a business perspective. Personal convictions enable business education students as learners to evaluate options to determine what is ethically right or wrong in the course of training to become teachers. Echoing Mazanec (2005), this study considered vignettes types as stories about individuals and situations, which make reference to important points in regard to perceptions, beliefs and attitudes. This study sought to establish the effect of adoption of narrative vignettes as experiential learning approach on ethical decision-making among business education students at University of Nairobi.

\subsection{Illustrations and Ethical Decision-Making}

Illustrations assist short-term and working memory by making more information readily available during business ethics instructional process. Supporting this position Boling, Eccarius, Smith and Frick (2004) argued that illustrations as vignettes present simultaneously all the information needed to explain a topic or perform a task in teaching business ethics. Illustrations, use of lines, boxes, arrows, space, color and typefaces. According to Goldstone and Son (2005) illustration reduce the relative distance between elements to communicate information about various ethical scenarios in teaching business ethics. Illustrations as vignettes present information at a glance with minimal graphical presentation that can be more efficient than words alone. In addition McCarron and Stewart (2011) noted that charts with multiple columns and rows can reveal the complex relationships between large amounts of business information to learners. Ideally, it would be difficult to present such information and even more difficult to comprehend in words alone. For this reason Spencer et al. (2015) argued that when learners read prose or hear exposition information is held in working memory long enough to develop ethical sensitivity necessary to decision making. This study considered illustration to present simultaneous information which would reduce the processing load on the working memory and thus help learners to develop individual ethical sensitivity

\subsection{Repertoire and Ethical Decision-Making}

This study focused on ethical decision-making in business as a complex cognitive and behavioral process that involves the use of knowledge and skills acquired from training. Acquisition of knowledge and skills according to Dane and Sonenshein (2014) is a product of class and life experiences as applied to particular scenarios in which the learner is required to make an ethical decision. Repertoires as vignettes provide life experiences as scenarios from which learners can make ethical decisions that affect a learning situation or business practice. Supporting these sentiments Deponte (2004) noted that use of repertoires as vignettes enhances learners' behavioral transformation by giving them an opportunity for reflection taking into account other peoples' views. Therefore, repertoire provides an opportunity for learners to get answers to ethical problems and dilemmas by enhancing decision-making processes. Kochan (2002) noted that through theatre and music, learners would have behavioral transformation with skills to manage ethical pressure from peers. It then follows that repertoires provides a positive behavioral transformation that helps in mitigating peer and cultural pressures. Further, Jeffries and Maeder (2004) writing on using vignettes in building and assessing instructional strategies asserted that repertoire enhances learners' ethical sensitivity through a positive behavioral transformation. Specifically, this study focused on the effect of adoption of repertoire as vignettes in teaching business ethics on ethical decision-making ability among business education students at University of Nairobi.

\subsection{Documentaries and Ethical Decision-Making}

Through use of documentaries, simulations of business ethics problems make learners react and act as though in a real-life situation. According to Krambia-Kapardis and Zopiatis (2011) documentaries would provide opportunities for learning leadership skills that would enable business education graduates develop ethical sensitivity as teachers. Vignettes in form of documentaries are described as written description, photograph, or videotaped scene as a brief glimpse of an educational situation. Dean and Beggs (2006) confirmed from survey 
participants sharing newspaper articles on real-world situations that documentaries stimulate learners to develop ethical sensitivity in decision-making. To enhance appropriate ethical sensitivity in decision making process there is a need to expose learners to a variety of business scenarios. Agreeing with these sentiments, Soenens, Berzcnsky, Vansteenkiste, Beyers and Goossens (2005) expressed that vignettes in form of documentaries provide short descriptions of business scenarios with specific references. Short descriptions of scenarios expose learners to ethical issues from business world and facilitate decision-making ability. Echoing Soenens et al (2005), this study expected documentaries to stimulate learners to develop business ethical ideology by providing minimal complexities and personalities than real life situations.

\subsection{Scripts and Ethical Decision-Making}

Scripts can be used to nurture business ethics through learner motivation to contribute to the common good as teachers. As noted by Deponte (2004), motivation can be acquired through sharing scripts with theoretical frameworks and stakeholder analysis models. Using scripts for critical reflection exercises and case analyses, individual learners or groups can identify with specific business scenarios. This according to Dane and Sonenshein (2014), will enable learners to bring own perspectives and options during discussions in business ethics class. Scripts set up scenarios with multiple answers and are flexible enough to enable learners to develop ethical sensitivity from a business perspective. Barkley, Cross and Major (2014) writing on collaborative learning techniques noted that scripts enhance disclosure and risk-taking in decision making process among learners. This is advantageous because scripts are considered relevant to the learning process at differential perspectives in class. Summing it up Krambia-Kapardis and Zopiatis (2011) posited that in using scripts, learners are typically expected to respond to various business scenarios with what they would do in a particular situation or how they think a third person would respond. Therefore it was necessary to establish the effect of scripts as vignettes on ethical decision making among business education students at the University of Nairobi

\subsection{Statement of the Problem}

Institutions of higher learning should work towards developing ethical sensitivity among learners for enhanced decision-making skills. This would make learners to become ethically intolerant to pressures that occur in both organization and community settings for illegal practices. Pedagogically vignettes have been used in business ethics classes to bring realistic scenarios that appropriately link theory and practice. To appropriately focus on ethical decision-making different types of vignettes have been adopted to entrench ethical decision making among learners in institutions of higher learning. However, little has been done to establish how effective various types of vignettes have affected ethical decision-making among business education students. This study focused on adoption of various types of vignettes in experiential learning approach for teaching business ethics purposely to develop instinct for decision-making among learners. Specifically, the study focused on the effect of narratives, illustrations, documentaries, repertoire and scripts vignettes on ethical decision making among business education students in University of Nairobi.

\section{Theoretical Framework}

This study adopted contingency framework for ethical decision-making. Contingency framework on decision-making was proposed by Ferrell and Gresham in 1985 and is a model in which ethical dilemma or issues emerging from the social or cultural environment are used as experiences for learning. The contingent factors that affect the decision maker are both individual and organizational. From individual perspective knowledge, values, attitudes, and intentions can be instilled through exposure to different ethical scenarios from business world as pointed by Dane and Sonenshein (2014). Various types of vignettes provide scenarios depicting organizational factors such as influence from peers or superiors as well as juniors while at the same time providing opportunities to experience different structural settings. 


\subsection{Conceptual Framework}

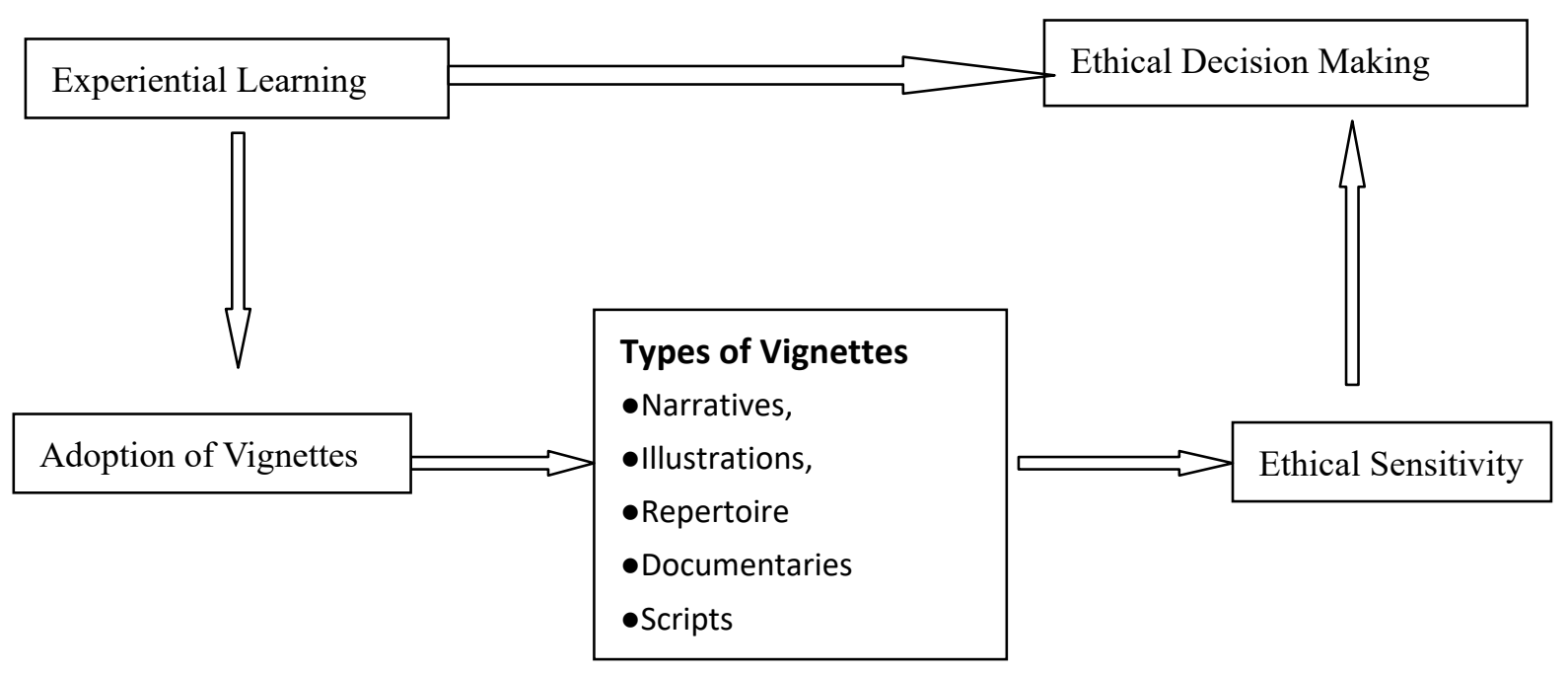

\section{Methodological Approach}

This study targeted 102 third year students undertaking business education at the University of Nairobi. Using random sampling a sample of 62 bachelor of education students were given questionnaires out of which 58 filled and returned. The data collected was quantitative in nature and SPSS version 23 was used in analyzing the results.

\section{Findings and Discussions}

Adoption of vignettes in teaching exposes learners to wide variety of ethical scenarios in the business world making the learners responsible global citizens. Ideally, different types of vignettes can be adopted to prompt critical thinking in business education students, which entrench ethical decision making. Information was obtained from 58 respondents out of 62 sampled business education students.

Table 1. Demographic information

\begin{tabular}{llll}
\hline Variables & Indicators & Frequency & Percentages \\
\hline Gender & Males & 33 & 56.9 \\
& Females & 25 & 43.1 \\
High School Attended & Boys Boarding & 12 & 20.7 \\
& Girls Boarding & 15 & 26.5 \\
& Boys Day & 3 & 5.9 \\
& Mixed Day & 22 & 38.2 \\
& Mixed Boarding & 6 & 10.3 \\
Business Experience & Yes & 31 & 53.4 \\
& No & 27 & 46.6 \\
\hline
\end{tabular}

\subsection{Gender}

Table 1 shows that $56.9 \%$ (33) of respondents were males and $43.1 \%$ (25) were females, an indication that both genders were adequately represented in the sample. This provided a basis for impartiality and fairness in discussions regard vignette types and ethical decision-making.

\subsection{High School Attended}

From Table 1 it is indicated $38.2 \%$ (22) of business education students at the University of Nairobi attended mixed day secondary schools. Majority of university students came from mixed day secondary schools because since introduction of Free Day Secondary Education (FDSE) policy parental preference has been influenced cost of education (Wagithunu, Muthee \&Thinguri, 2014). Secondly, as noted by Chetambve and Sakwa, (2013) many day secondary schools have been established through Constituency Development Fund (CDF) to provide parents with affordable option for their children. Table 1 also indicates that for those parents who can afford there is a greater preference for girls to attend boarding secondary schools compared to their male counterparts (Oyier, 
Odundo, Ganira and Wangu (2015). Specifically, Table 1 shows that 26.5\% (15) of the respondents were girls who attended boarding schools and 20.6\% (12) boys respectively. The study findings on parental preference for boarding secondary schools for girls, is in concurrence with Oketch, Mutisya and Sagwe (2012) assertion on their concern on security and less distractions from social life. Last but not least school attended has influence on ethical decision-making. This was confirmed by Bentley (2012) that schools with a liberal orientation provide opportunities for learners to make decisions.

\subsection{Business Experience}

Table 1 indicates that 53.4\% (31) of students had business experience while 46.6\% (27) did not. Further analysis revealed that majority with business experience were male students $(36.3 \%)$ compared to females $(17.6 \%)$. As much as the findings indicate that more male students had business experience Shava and Chenesai (2014) in a study from South Africa revealed that there is no statistically significant between gender and the level of business experience. However according Dane and Sonenshein (2014) there are contradictory results on the influence of previous experience on ethical decision making at the workplace. This made it hard to build an argument relationship between experience ethical decisions making in this study.

\subsection{Effects of Vignette Types on Ethical Decision Making}

Different types of vignettes can be adopted to prompt critical thinking in business education students to entrench ethical decision-making. This study considered vignettes in form of narrative, illustrations, repertoires, documentaries as instructional resources for instilling ethical sensitivity among business education students.

\subsection{Narratives}

Teaching business ethics using vignettes in form of narratives could provide learners with practical dilemmas from which learners would develop ethical sensitivity. In this study respondents were ask the extent they agree that problem analysis through narratives enhances judgment from varied perspectives and the results presented in Table 2.

Table 2. Narrative Vignettes

\begin{tabular}{lll}
\hline & Frequency & Percentages \\
\hline Strongly Agree & 35 & 60.6 \\
Agree & 19 & 33.3 \\
Uncertain & 4 & 6.1 \\
Disagree & 0 & 0 \\
Strongly Disagree & 0 & 0 \\
Total & $\mathbf{5 8}$ & $\mathbf{1 0 0 . 0}$ \\
\hline
\end{tabular}

From Table 2 , the study results indicate that $60.6 \%$ of business education students strongly agreed that problem analysis through narratives enhances judgment from varied perspectives and $33.3 \%$ agreed. This is an indication that narratives provide learners with business dilemmas from which they would develop ethical sensitivity. As noted by Sims and Sauser (2011), the findings of this study confirms that narratives can be used by teachers to establish the unique ideas, insights and challenges faced by individual learners in making ethical decisions. By providing learners with practical dilemmas, narratives enable learners to develop ethical sensitivity. This is in concurrence with McCarron and Stewart (2011) argument that adoption of vignettes teaching narratives help learners in problem analysis and developing judgment criteria for varied perspectives. With only $6.1 \%$ of the respondents being uncertain, the results indicate that narratives help learners to objectively come up with ethical decisions in business. In helping learners to objectively come up with ethical decisions, narrative guide evaluation of options to determine what is morally right or wrong. Vignettes as narratives enable learners to make reference points that would shape perceptions, beliefs and attitudes.

\subsection{Illustrations}

Vignettes in form of illustrations present simultaneously all the information needed to explain a topic or perform a task in teaching business ethics. The lines, boxes, arrows, space, color and typefaces in an illustration assist short-term and working memory by making more information readily available during business ethics instructional process. Business education students were asked to state the extent to which illustrations help in acquisition of cognitive ethical skill among learners and the responses presented in Table 3. 
Table 3. Response on illustrations

\begin{tabular}{lll}
\hline & Frequency & Percentage \\
\hline Strongly Agree & 30 & 51.5 \\
Agree & 18 & 30.3 \\
Uncertain & 8 & 15.2 \\
Disagree & 2 & 3.0 \\
Strongly Disagree & 0 & 0 \\
Total & $\mathbf{5 8}$ & $\mathbf{1 0 0 . 0}$ \\
\hline
\end{tabular}

Table 3 indicates that $51.5 \%$ strongly agreed and $30.3 \%$ agreed that illustrations help in acquisition of cognitive ethical skill among learners. This is an indication learners acknowledged that illustration present information at a glance that can entrench acquisition of cognitive ethical skill among learners. With minimal graphical presentation that can are more efficient than words alone can reduce the relative distance between elements to communicate information about various ethical scenarios in teaching business ethics (Goldstone \& Son, 2005). However, the fact that $15.2 \%$ were uncertain and $3.0 \%$ disagree is an indication that charts with multiple columns and rows can be complex to some learners. This complexity is however beneficial in revealing relationships in large amounts of business information. In line with McCarron and Stewart (2011) assertion, these findings illustrations confirm that makes it easy to comprehend such information than when in words alone. Finally, when learners read prose or hear exposition information is held in working memory long enough to develop ethical sensitivity necessary to decision making (Spencer et al. 2015). Ideally, illustration vignettes simultaneous present information, which would reduce the processing load on the working memory and thus help learners to develop individual ethical sensitivity

\subsection{Repertoire}

Ethical decision-making in business is a complex cognitive and behavioral process that involves the use of knowledge and skills acquired from training. In this study, respondents were asked the extent to which repertoire provides a behavioral transformation in ethical decision making. Table 4 shows analysis of the results

Table 4. Response on repertoire

\begin{tabular}{lll}
\hline & Frequency & Percentages \\
\hline Strongly Agree & 32 & 54.5 \\
Agree & 14 & 24.2 \\
Uncertain & 5 & 9.1 \\
Disagree & 5 & 9.1 \\
Strongly Disagree & 2 & 3.0 \\
Total & $\mathbf{5 8}$ & $\mathbf{1 0 0 . 0}$ \\
\hline
\end{tabular}

Table 4 indicates that $54.5 \%$ strongly agreed and $24.2 \%$ agreed that repertoire provides a behavioral transformation in ethical decision-making. This confirms that behavioral transformation is achieved as a product of class and life experiences derived from scenarios provided in repertoire (Dane and Sonenshein, 2014). Repertoire provides opportunity in which learners acquire knowledge and skills from reflection of other peoples' views which then enhances behavioral transformation. The study findings are therefore a confirmation that theatre and music can lead into behavioral transformation and skills to manage ethical pressure from peers (Kochan, 2002). The result also showed that $9.1 \%$ were uncertain; another $9.1 \%$ disagreed while $3.0 \%$ strongly disagreed. This was an indication that some respondents did not consider repertoire to provide a positive behavioral transformation that could help in mitigating peer and cultural pressures. This is contrary to Jeffries and Maeder (2004) assertion that that repertoire enhances learners' ethical sensitivity through a positive behavioral transformation.

\subsection{Documentaries}

Documentaries are described as written description, photograph, or videotaped scene as a brief glimpse of an educational situation. This study sought from business education students the extent they agree that documentaries provide short descriptions of real ethical business situations and the results presented in Table 5 . 
Table 5. Response on documentaries

\begin{tabular}{lll}
\hline & Frequency & Percentages \\
\hline Strongly Agree & 28 & 48.5 \\
Agree & 25 & 42.4 \\
Uncertain & 5 & 9.1 \\
Disagree & 0 & 0 \\
Strongly Disagree & 0 & 0 \\
Total & $\mathbf{5 8}$ & $\mathbf{1 0 0 . 0}$ \\
\hline
\end{tabular}

Results in Table 5 indicate that slightly more than $90 \%$ of respondents were in agreement that documentaries provide short descriptions of real ethical business situations. Specifically, $48.5 \%$ strongly agreed and $42.5 \%$ agreed that documentaries would provide opportunities for learning skills that would enable learners develop ethical decision-making skills (Krambia-Kapardis and Zopiatis, 2011). These findings confirm that documentaries as simulations of business dilemmas make learners react and act as though they were in a real-life situation. These findings echo Dean and Beggs (2006) assertion that documentaries stimulate learners to develop individual business ethical ideology. Table 5 also shows that $9.1 \%$ of the respondents were uncertain that documentaries provide short descriptions of real ethical business situations. This group could not agree that documentaries enhance appropriate ethical behavior in decision-making process. With a small number of respondents not being uncertain there is still a need to encourage individual to develop business ethical ideology. This can be achieved as suggested by Soenens et al (2005) through shorter versions of documentaries. Short description of situations is an important consideration in ethical decision-making process as stressed by Soenens et al (2005) they can stimulate learners to develop own individual business ethical ideology by providing minimal complexities and personalities than real life situations.

\subsection{Scripts}

Script can be used to nurture business ethics learners' motivation to contribute to the common good as teachers. This study sought from business education students the extent they believe scripts build ethical sensitivity through sharing of reflection exercises and the results presented in Table 6

Table 6. Response on scripts

\begin{tabular}{lll}
\hline & Frequency & Percentages \\
\hline Strongly Agree & 33 & 57.6 \\
Agree & 23 & 39.4 \\
Uncertain & 0 & 0 \\
Disagree & 2 & 3.0 \\
Strongly Disagree & 0 & 0 \\
Total & $\mathbf{5 8}$ & $\mathbf{1 0 0 . 0}$ \\
\hline
\end{tabular}

Table 6 indicates that $57.6 \%$ of the respondents strongly agreed and 39.4\% agreed that scripts build ethical sensitivity through sharing of reflection exercises. This give $97 \%$ agreement that scripts builds ethical sensitivity. In concurrence with Deponte (2004) scripts motivates through critical reflection exercises and case analyses. In reality scripts can enable individual learners to identify specific business scenarios through sharing scripts with theoretical frameworks and stakeholder analysis models. This seems to be confirmation by respondents agreement that scripts enable learners to bring own perspectives and options (Dane \& Sonenshein, 2014). In class discussions scripts set up scenarios in which there is no one right answers to elicit discussions that could easily lead to learners' developing individual business ethical sensitivity, even through $3 \%$ disagreed. Those who disagreed could have done that with the belief that scripts enhance disclosure and risk-taking (Barkley et al 2014). However, it is worth noting that in using scripts, learners typically expected to respond to various business scenarios with what they would do in a particular situation or how they think a third person would respond.

\section{Conclusion}

Vignettes range from text and images plus other forms of stimuli learners respond during experiential learning. They include written descriptions, photographs or videotaped scenes that provides brief glimpse what happens in 
the business world for an educational purpose. From this study it has been established that vignettes are effective in engaging learners' interests in relevance to real business world as far as ethical decision-making is concerned. It was established that different types of vignettes could be used to provide specific business scenarios in teaching ethics. For example narratives are vital part of ethical training and decision-making from a cultural perspective and are used in traditional transmission of values. Narratives as vignettes situate values as course content and stimulate discussion towards enhancing decision-making. In general teaching business ethics using vignettes in form of narratives provide learners with practical dilemmas from which learners would develop ethical sensitivity. The findings of this study confirm that narratives can be used by teachers to establish the unique ideas, insights and challenges faced by individual learners in making ethical decisions.

As much as narrative guide evaluation of options to determine what is morally right or wrong, illustrations present simultaneously all the information needed to explain a topic or perform a task in teaching business ethics. This study established that illustrations help in acquisition of cognitive ethical skill among learners. At a glance, illustration presents information that can entrench acquisition of cognitive ethical skill among learners with minimal graphical presentation. This as noted from the study is more efficient than words alone and reduces the relative distance between elements to communicate information about various ethical scenarios in teaching business ethics. However, as much as use of charts with multiple columns and rows can be complex, they are beneficial in revealing relationships in large amounts of business information. Findings of this study confirmed that illustrations make it easy to comprehend complex information than when learners read prose or hear exposition. Such information is held in working memory long enough to develop ethical sensitivity necessary to decision making. In conclusion illustration simultaneously present information in a way that it reduces the processing load on the working memory and thus help learners to develop individual ethical sensitivity.

Repertoire enhances learners' ethical sensitivity through positive behavioral transformation. As vignettes, repertoire provides business ethics learners with opportunity draw meanings from observing others. Observed actions contain visual and non-visual cues which present a realism that resembles real-life ethical decision-making situations. Findings from this study confirmed that behavioral transformation is achieved as a product of class and life experiences derived from scenarios provided in repertoire. Repertoire therefore provides opportunity in which learners acquire knowledge and skills from reflection of other peoples' views which then enhances behavioral transformation. Repertoire in form of theatre and music can lead into behavioral transformation and skills to manage ethical pressure from peers. Given that ethical decision- making in business is a complex cognitive and behavioral process, knowledge and skills acquired from training using repertoire. This might sometimes require dramatizing or singing to elicit ethical sensitivity among the learners

Documentaries as vignettes provide short descriptions of real ethical business situations and would entrench decision making among learners. Videotaped or live events provide more information that would enable learners develop ethical decision making skills than written narrative. Findings of this study confirm that documentaries as simulations of business dilemmas make learners react and act as though they were in a real-life situation. This will stimulate learners to develop ethical sensitivity that is ideal in decision making in a given business situation. Learners can be encouraged to develop individual business ethical ideology through adoption of shorter versions of documentaries. This would be an important consideration in ethical decision-making process through minimal complexities and personalities than real life situations.

Scripts can build ethical sensitivity through sharing of reflection exercises. In practice scripts can be used to nurture business ethics learners' motivation to contribute to the common good as teachers. In reality scripts can enable individual learners to identify specific business scenarios through sharing scripts with theoretical frameworks and stakeholder analysis models. Findings from this study were a confirmation that scripts enable learners to bring own perspectives and options. In class discussions scripts set up scenarios in which there is no one right answers to elicit discussions that could easily lead to learners' developing individual business ethical sensitivity. Even though some people belief that scripts enhances disclosure and risk-taking, it is worth noting that their usage evokes responses on particular situations and thinking about how the third person would respond.

\section{Recommendations and Policy Implications}

This study is recommending that business teachers need to be advised to adopted different types of vignettes in teaching. On policy, this study recommends that at school level adequate budgetary allocations for vignettes development should be in place to ease usage in class. This is because cost implication tend to be expensive, especially documentaries. Finally, the study recommends further research to establish how much vignettes have been used in schools for business studies 


\section{References}

Barkley, E. F., Cross, K. P., and Major, C. H. (2014). Collaborative learning techniques: A handbook for college faculty.

Bentley, T. (2012). Learning beyond the classroom: Education for a changing world. Routledge.

Boling, E., Eccarius, M., Smith, K., \& Frick, T. (2004). Instructional illustrations: Intended meanings and learner interpretations. Journal of Visual Literacy, 24(2), 185-204.

Chetambve, H. N., \& Sakwa, M. (2013). Effects of Financial Training on Financial Performance of Schools in Kenya: A Survey of Administrators of Secondary Schools in Trans-Nzoia County. International Journal of Academic Research in Business and Social Sciences, 3(10), 214-220.

Dane, E., \& Sonenshein. (2014): On the role of experience in ethical decision making at work. Organizational Psychology Review, 5(1), 74-96

Dean, K. L., \& Beggs, J. M. (2006). University Professors and Teaching Ethics: Conceptualizations and Expectations. Journal of Management Education, 30(1), 15-44.

Deponte, A. (2004). Linking motivation to personality: Causality orientations, motives and self-descriptions. European Journal of Personality, 18(1), 31-44.

Goldstone, R. L., \& Son, J. Y. (2005). The transfer ofscientific principles using concrete and idealized simulations. Journal of the Learning Sciences, 14(1), 69-110.

Harland, T. (2014). Learning about case study methodology to research higher education. Higher Education Research and Development, 33(6), 1113-1122.

Jeffries, C., \& Maeder, D. W. (2004). Using vignettes to build and assess teacher understanding of instructional strategies. The Professional Educator, 26(1\&2), 17-28.

Kochan, T. A. (2002). Addressing the Crisis in Confidence in Corporations: Root Causes, Victims, and Strategies for Reform. Academy of Management Executive, 17, 139-141

Krambia-Kapardis, M., \& Zopiatis, A. (2011). Personal values of accountants and accounting trainees in Cyprus. Business Ethics: A European Review, 20(1), 59-70.

Macik-Frey, M., Quick, J. C., \& Quick, J. D. (2007). Interpersonal communication: The key to social support for preventive stress management (pp. 265-292). In C. L. Cooper (Ed.), Handbook of Stress, Medicine, and Health (2nd ed.). Boca Raton: CRC Press.

Mazanec, J. A. (2005). New methodology for analyzing competitive positions: A demonstration study of travelers attitude toward their modes of transport. Tourism Analysis, 9, 1-10.

McCarron, M. C. E., \& Stewart, D. W. (2011). A Canadian Perspective on Using Vignettes to Teach Ethics in Psychology. Canadian Psychological Association, 52(3), 185-191.

Melé, D. (2012). Management Ethics: Placing Ethics at the Core of Good Management. Palgrave Macmillan, Houndmills, UK.

Odundo, A. P., \& Gunga, S. O. (2013). The effects of application on institutional methods on learner achievement in business in secondary schools in Kenya. International Journal of Education and Research, $1(5)$.

Oketch, M., Mutisya, M., \& Sagwe, J. (2012). Do poverty dynamics explain the shift to an informal private schooling system in the wake of free public primary education in Nairobi slums? London Review of Education, 10(1), 3-17. http://dx.doi.org/10.1080/14748460.2012.659056

Oluoch, P. M., \& Odundo, P. A. (2018). Influence of Vignettes Constructions on Ethical Decision among Business Education Students. World Journal of Educational Research, 5(2).

Oyier, C. R., Odundo, P. A., Ngaruiya, B., \& Mwangi, J. (2017). Science Teachers and Budget Planning for Instructional Resources in Secondary Schools in Nairobi, Kenya. Asian Education Studies, 2(3).

Oyier, C. R., Odundo, P. A., Obat, R. A., Ganira, K. L., \& Okondo, J. O. (2015). Parental Choice and Learner Achievement in Primary Education in Rachuonyo Sub County, Kenya: Focusing on Quality of Education. World Journal of Education, 5(5). 
Shava, H., \& Chenesai, E. (2014). Gender Differences in Business Related Experience amongst Smmes Owners in King Williams Town, South Africa: A Comparative Analysis. Mediterranean Journal of Social Sciences, $5(20)$.

Sims, R. R., \& Sauser, W. I. (2011). Experiences in Teaching Business Ethics. Contemporary Human resources Journal.

Soenens, B., Berzcnsky, M. D., Vansteenkiste, M., Beyers, W., \& Goossens, L. (2005). Identity styles and causality orientations: In search of the motivational underpinnings of the identity exploration process. European Journal of Personality, 19(5), 427-442.

Wagithunu, N. M., Muthee, J., \& Thinguri, R. (2014). A Critical Analysis of School Principals' Competence in Financial Management in Kenya: Accountability in Educational Planning and Management. Journal of Education and Practice, 5(25).

\section{Copyrights}

Copyright for this article is retained by the author(s), with first publication rights granted to the journal.

This is an open-access article distributed under the terms and conditions of the Creative Commons Attribution license (http://creativecommons.org/licenses/by/4.0/). 